must be mentioned that in a paper just to hand, H. W. Schmidt (Phys. Zeit., I909, p. 6) gives the new value 4100 for these rays, making the usual assumption, apparently, that they were homogeneous. I obtained the value as high as 6500 for a small proportion of the rays, but no definite extreme upper limit can be assigned, and it is probable that some exist with a value even higher. Some of the $\beta$ rays of radium possess, so far as I have yet been able to see, values for $\mathrm{H} \rho$ above 900o, and probably the extreme upper limit is not reached at 11,000 . The extreme value found in Kaufmann's celebrated experiments was 4500 , but it must be remembered that he worked with the less sensitive-although more precise-photographic method. For $\mathrm{H} \rho$ to have values so high as those recorded the velocity of the rays must be but a small fraction of I per cent. below that of light, and their mass must be at least four times in the case of uranium and six times in the case of radium the normal value found at lower speeds. I have had in mind the possibility that the effect might be due to a secondary radiation, and particularly in view of Bragg's theory of the nature of the $\gamma$ rays, to a secondary radiation from the air; but $I$ have not been able to prove that the rays are other than primary $\beta$ rays. The direction of their deviation was specifically tested.

FREDERYCK SODDY.

Physical Chemistry Laboratory, University of Glasgow.

P.S., January 26.-I have omitted to mention that Paschen (Ann. Phys., 1904, xiv., 389) obtained evidence of the existence of $\beta$ rays from radium with a value for $\mathrm{H} \rho$ so high as 8000 .

F. S.

The Origin of the Aborigines of Tasmania.

In kindly reviewing my little book on the Discovery and Settlement of Port Mackay, Queensland, in NATURE of September 24, 1908, the reviewer, "J. W. G.," states that Mr. Ling Roth " objects to calling the blackfellows aborigines, as he holds that Australia was first occupied by a negroid people who have been supplanted by the present race. This view, well known from its adoption by [the late] Sir William Flower, appears to be now generally discredited, owing to the lack of evidence in its support."

Since, the above was written I have received from Sir William Turner his recently published memoir on the "Craniology, Racial Affinities, and Descent of the Aborigines of Tasmania" (Trans. Roy. Soc. Edin.). In this monograph Sir William Turner comes to the same conclusion as $I$ have regarding the origin of the Tasmanians, arriving there by a totally different and probably more scientific method than that which I have been able to follow. He says (p. 394) :- “" Though, as has already been stated, a woolly-haired race is not now represented in Australia, the tendency of the South Australians to show Tasmanian characters in the cranial vault is worthy of consideration, in this particular, as an indication of the probable route of migration and of racial affinity. . . The evidence seems to be in favour of the descent of the Tasmanians from a primitive Negrito stock, which migrated across Australia, rather than by the route of the Melanesian Oceanic islands lying to the north and east of the Australian continent." Linguistic evidence appears also to favour the view. In the December (1908) number of Man (p. 185) Father Schmidt ("Classification of Australian Languages") tells us that "the languages of S.E. Australia agree with Tasmanian in one of the most important points-the position of the affixless genitive."

I therefore venture to think that the more the question is studied the more does it seem probable that the real aborigines of Australia were the forefathers of the unhappy people we have known as Tasmanians.

Halifax, Yorks, December 28, 1908.

$$
\text { H. Ling - Roth. }
$$

Mr. Ling Roth's letter involves two questions. The term " native" in Australia means white people born in Australia; the blackfellows are known as aborigines. It seems to me, therefore, only inviting misunderstanding

No. 2048, vOL. 79] and mistakes to reject the accepted Australian use of the word aborigines in a book dealing with Australia.

The second question is the possible descent of the extinct Tasmanians from the race that occupied Australia before the European colonisation. The very important memoir by Sir William Turner on the craniology of the Tasmanians (Trans. Roy. Soc. Edin., vol. xlvi., pp. 365-403, three plates) was not published at the date of the review; but though he admits the probable passage of the Tasmanians across Australia, he adds to the difficulty of connecting the Tasmanians with the present Australian aborigines.

On pp. $3^{8} 7-8$ of his memoir he gives a long list of important characters in which the Australian skulls differ from those of the Tasmanians, and he concludes this catalogue of differences as follows:- "From the consideration of these characters the skulls support the opinion, based on the study by so many observers of the external features, that the existing aborigines of Australia are distinct from the Tasmanians, although the presence, in a proportion of the natives of South and West Australia, of skulls in which the height was less than the breadth, the not unfrequent sunk sagittal suture, the more marked parietal eminences, and the antero-posterior parietal depressions, point to a possible amount of intermixture and racial affinity of these Australian tribes with the Tasmanians." (The italics are mine.)

That " a proportion" of the aborigines of South Australia should have skulls approximating to those of the Tasmanians is easily explained. Tasmanians were taken to South Australia by the sealers, and gave rise to half-castes. The occasional Victorian aborigines with woolly hair and other Tasmanian features had probably the same origin.

Sir William Turner's memoir may be taken as the final dismissal of Sir William Flower's view that the Tasmanians were Melanesian, and the weight of authority, including Huxley and Mr. Ling Roth, that they were Negrito is now overwhelming; but this adds to the difficulty of alliance between the Tasmanians and the Australians. Sir William Turner says (p. 389), " the term Negrito should be limited to ... black-skinned, woolly-haired people with small brachycephalic heads, jaws not very projecting, nose not so flattened, nostrils not so wide as in the Negro, and of dwarf-like stature." These characters are not.those of the Australian aborigines, with their long, straight hair, hyperdolichocephalic heads, projecting jaws, extraordinarily wide nostrils, and tall stature.

The absence of evidence of the Tasmanian race in the well-searched drifts and gravels of Australia renders their passage across Australia improbable. I am, of course, glad to find that Sir William Turner adds his authority to the view of the Negrito affinity of the Tasmanians, but it does not follow that they crossed the mainland of Australia, a view that has been abandoned by some of those who formerly adopted it.

It would be strange if the Australian and Tasmanian languages had not some points of affinity, but the differences have been usually regarded as fundamental. $\mathrm{Mr}$. Ling Roth has recognised Andamanese affinities in the language of the Tasmanians, which is, of course, consistent with Sir William Turner's conclusions, but it does not help to ally the Tasmanians and Australians.

J. W. G.

\section{Warm Months in Relation to Sun-spot Numbers.}

THE following method, applied to Greenwich data, seems to yield support to the view that sun-spots mean, on the whole, warmth in this region.

Taking your sun-spot numbers (from I84I), pick out the 22 highest (group A) and the 22 lowest (group B) -22 is about a third of the series. Next, confining attention to the year after each year of group A, note how many warm Januarys, Februarys, and so on, there were in the 22 years. This gives the series $(a)$ below. Do the same in the case of group B, getting the series $(b)$. Smooth each of these series with sums of 3 , getting $\left(a^{\prime}\right)$ and $\left(b^{\prime}\right)$. On comparing $\left(a^{\prime}\right)$ with $\left(b^{\prime}\right)$ the former is found to be throughout in excess of the latter, as shown. 